\title{
Not all developmental assets are related to positive health outcomes in college students
}

\author{
Keith J Zullig ${ }^{1 *}$, Daniel A Teoli ${ }^{1}$ and Rose Marie Ward ${ }^{2}$
}

\begin{abstract}
Background: The purpose of this investigation was to model the relationships between developmental assets, life satisfaction, and health-related quality of life (HRQOL) among a stratified, random sample $(n=765,56 \%$ response rate) of college students.

Methods: Structural equation modeling techniques were employed to test the relationships using Mplus v4.21; Model evaluations were based on 1) theoretical salience, 2) global fit indices (chi-square goodness of fit, comparative fit index: CFI and Tucker-Lewis Index: TLI), 3) microfit indices (parameter estimates, root mean squared error of approximation: RMSEA and residuals) and 4) parsimony.

Results: The model fit the data well: $\chi^{2}(n=581,515)=1252.23, C F I=.94, T L I=.93$ and RMSEA $=.05$. First, participants who reported increased Family Communication also reported higher levels of life satisfaction. Second, as participants reported having more Non-Parental Role Models, life satisfaction decreased and poor mental HRQOL days increased. Finally increased Future Aspirations was related to increased poor mental HRQOL days. Results were variant across gender.

Conclusions: Preliminary results suggest not all developmental assets are related to positive health outcomes among college students, particularly mental health outcomes. While the findings for Family Communication were expected, the findings for Non-Parental Role Models suggest interactions with potential role models in college settings may be naturally less supportive. Future Aspirations findings suggest college students may harbor a greater temporal urgency for the rigors of an increasingly competitive work world. In both cases, these assets appear associated with increased poor mental HRQOL days.
\end{abstract}

\section{Background}

Positive youth development (PYD) first originated as a conceptual approach of developing assets within youth as opposed to removing risk factors via "deficit-focused strategies" [1]. Evidence suggests a relationship exists between the number of assets possessed and the number of thriving indicators within an individual (such as possession of leadership qualities, display of resiliency, and achieved success in school) [2]. Building upon this support, PYD considers the strengths of youth and values the contributions they can make toward healthy development by maximizing these individual strengths through meaningful societal roles and community-based activities [3].

\footnotetext{
* Correspondence: kzullig@hsc.wvu.edu

'Department of Community Medicine, West Virginia University, Morgantown, W, USA

Full list of author information is available at the end of the article
}

PYD is often assessed through the Search Institute's Developmental Asset Framework [4]. This framework suggests that 40 primary assets may affect healthy youth development. These assets are grouped into either internal or external assets. Internal assets are skills, values, and commitments that stem from within an individual including (but not limited to) humility, appropriate decision-making, and a sense for his or her own purpose in life. Internal assets categories include commitment to learning, positive values, social competencies, or positive identity. In contrast, external assets develop outside of an individual. External assets are positive experiences and interactions gained from one's family, non-parental role models, school, community, and service groups. External asset categories include support, empowerment, boundaries and expectations, or constructive use of time [5]. When the internal and external assets are in a balanced positive state of existence, PYD can occur [6].
C Biomed Central

() 2011 Zullig et al; licensee BioMed Central Ltd. This is an Open Access article distributed under the terms of the Creative Commons Attribution License (http://creativecommons.org/licenses/by/2.0), which permits unrestricted use, distribution, and reproduction in any medium, provided the original work is properly cited. 
Increased asset development may serve as an important protective factor for individuals [7]. For example, those who possess increased developmental assets are less likely to report violent and aggressive behavior [8]; tobacco use [9]; risky sexual behavior [10,11]; and alcohol and drug use [12]. These findings may be especially pertinent to college students, who constitute a population often exposed to unusual stressors such as living in a new location, pressure for high academic achievement, immediate availability of illegal substances, and increased risk of dangerous sexual behaviors. These stressors can effectively serve as barriers to a smooth transition for students from their homes to an independent college environment [13,14]. Moreover, research also suggests that the total number of assets possessed by a student is approximately two times more effective in anticipating future achievement than are other predictive measures (e.g., race/ethnicity, family composition and socioeconomic status) [3]. For instance, the correlations between academic achievement (GPA) and the total number of assets in an individual was .45 for males and .35 for females in a recent study [15].

While developmental assets appear to be protective against engagement in risky behaviors, little is known about the relationship between developmental assets and one's quality of life (QOL). According to Diener [16], improving QOL is important for enriching an individual's overall well-being. QOL consists of two dimensions: subjective and objective. Objective QOL examines issues external to an individual such as annual income level, neighborhood crime rates, and personal housing quality. Alternatively, subjective QOL consists of judgments of one's overall life in different domains including, but not limited to, self, family life, and romantic relationships. Subjective QOL can be further separated into life satisfaction and health-related quality of life (HRQOL) [17]. Specifically, life satisfaction is a cognitive conclusion regarding the quality of one's own life in comparison with a self-imposed standard [18]. The outcome of comparing actual circumstances vis-à-vis personal standards will render individual global life satisfaction judgments as positive or negative in nature [19]. The United States (US) Centers for Disease Control and Prevention (CDC) define HRQOL as "an individual's or group's perceived physical and mental health over time" [20]. On the micro scale, HRQOL observes physical and mental health levels of an individual. On the macro scale, an entire population (or student body) can be analyzed for the impact that policies, resources, and conditions (i.e., developmental assets) have upon that respective population's health.

Similar to a lack of developmental assets $[8,9,11,12]$, lower levels of life satisfaction are related to increased violent and aggressive behavior [21], substance use [22], and risky sexual behavior [23]. Reduced life satisfaction is also related to unhealthy dieting and weight perceptions [24-26], suicide ideation [27] and a sedentary lifestyle [28]. In light of these established relationships with life satisfaction, subjective quality of life is an important facet of health research that is often overlooked [29]. Unfortunately, the literature contains little research exploring the relationship between life satisfaction and developmental assets in the context of PYD. While one study by Valois et al. [30] indicates a significant positive relationship between increased developmental assets and life satisfaction, the findings are limited to one study of public middle school students. No studies examine a college student population. Therefore, one aim of this study is to explore the relationship between developmental assets and college student life satisfaction.

A second aim of this study is to explore the relationship between developmental assets and HRQOL. According to the US CDC [31], "fair or poor" self-rated health was reported by $9.7 \%$ of 18 -24 year olds in 2007 - an increase from $6.5 \%$ in 1993 . Similarly, the "mean physically unhealthy days" (out of the prior 30 ) was an average of 4.3 days in 2006 and the mean "mentally unhealthy days" (out of the prior 30 ) was approximately 6.0 days in 2006 [31], both of which have increased since 1996. However, no adult or adolescent literature explores the relationship between developmental assets and HRQOL.

Therefore, the purpose of this study is to explore the concurrent relationships between the developmental assets, life satisfaction, and HRQOL among college students. The need for a more thorough understanding of these relationships is further bolstered by two important findings: the current generation of teenagers exhibit overall worse mental health [32] and higher levels of anxiety [33] in comparison to previous generations. The current study extends the extant literature by 1 ) exploring any relationships between the developmental assets, life satisfaction, and HRQOL outcomes and by 2) suggesting which developmental assets are most strongly related to both life satisfaction and HRQOL. This research may be subsequently used to direct PYD approaches in college settings.

\section{Methods \\ Sampling Method}

During February 2007, 1,300 students 18 years of age or older were randomly selected from a Midwestern university's email database to participate in an internetbased health survey. Equal numbers of students from each academic class were selected at random (i.e. a stratified random sample) via the uniform distribution number generator function in SAS [34]. The methodology provided each student an equal probability of being selected as a participant in the investigation's sample to 
produce a representative sample of the university's students. The sample database included student names, upto-date mailing addresses, and current email addresses.

Using internet survey methods [35] approved by the referent university's institutional review board, selected students $(n=1,300)$ were sent an invitation to participate. Selected students were notified that if they participated in the investigation, they would receive a coupon to an off-campus café (redeemable for a single specialty drink of choice). Seven days after the initial solicitation, a second email containing a clickable hyperlink to the questionnaire was sent to the potential participants. Those who clicked the hyperlink were first directed to an informed consent statement that explained the pertinent research procedures and specific active measures being taken to protect participants' privacy. At the conclusion of the survey, all potentially identifying information details were separated from the responses and stored in a separate data storage location (thus making responses anonymous). A total of 723 surveys were completed for a $56 \%$ response rate.

\section{Participants}

Sample demographics are provided in Table 1. The referent institution is a four-year, public university of midsize in the Midwestern United States. Approximately 14,265 students of the 16,262 total student population are Caucasian $(86 \%)$ and only $2 \%$ of students are above the age of 24. The composition of the University's undergraduate body is $46 \%$ male and $54 \%$ female. The percentages of freshman, sophomore, junior and senior students comprising the student body are $27 \%, 27 \%$, $21 \%$ and $24 \%$, respectively. While females are slightly overrepresented and males are underrepresented in this

Table 1 Sample Demographics

\begin{tabular}{ll}
\hline Characteristic & Number of Respondents ${ }^{(\mathbf{N}=\mathbf{7 2 3})}$ \\
\hline $\begin{array}{ll}18 \mathrm{yrs} \\
19 \mathrm{yrs}\end{array}$ & $93(12.9 \%)$ \\
$20 \mathrm{yrs}$ & $172(23.8 \%)$ \\
$21 \mathrm{yrs}+$ & $177(24.5 \%)$ \\
Year & $281(38.9 \%)$ \\
First year & \\
Sophomore & $193(27.7 \%)$ \\
Junior & $155(21.4 \%)$ \\
Senior & $203(28.1 \%)$ \\
Gender & $172(23.8 \%)$ \\
Male & \\
Female & $232(32.1 \%)$ \\
Race & $491(67.9 \%)$ \\
White & $654(90.5 \%)$ \\
Nonwhite & $69(9.5 \%)$ \\
\hline
\end{tabular}

sample, the racial and academic year demographics are quite representative of the campus as a whole.

\section{Measures \\ Developmental Assets}

Based on the work of Oman et al. [36], the developmental asset measure used in this study was developed and validated for college students [37]. The survey contains 28 items and measures eight developmental assets. The first asset is "Family Communication" with three items (response options $1=$ almost never; $2=$ some of the time; 3 = usually; 4 = almost always). A sample Family Communication item is "How often does your mother, father, or another adult at your home try to understand your point of view?" The second asset is "Peer Role Models" also with three items (response options $1=$ almost never; $2=$ some of the time; 3 = usually; $4=$ almost always); a sample item is "Are most of your friends responsible?" The third asset is "Future Aspirations" with two items (response options $1=$ not important at all; 2 = somewhat important; 3 = very important; 4 = extremely important); a sample item is "As you look into the future, how important is it that you do well in school?" The fourth asset is "Responsible Choices" with three items (response options $1=$ not at all like you; $2=$ a little like you; $3=$ mostly like you; $4=$ very much like you); a sample item is 'You can say 'no' to activities you think are wrong." The fifth asset is "Non-Parental Adult Role Models" with four items (response options $1=$ strongly disagree; 2 = disagree; 3 = agree; 4 = strongly agree); a sample item is "You know at least one adult on campus you could talk with about personal problems." The sixth asset is "Spirituality" and contains six items (response options 1 = strongly agree; 2 = agree; 3 = disagree; 4 = strongly disagree); a sample is "Spirituality is very important to me." The seventh asset is "Community Involvement" contains four items (response options $1=$ not at all like you; $2=$ a little like you; $3=$ mostly like you; 4 = very much like you); a sample item is "You work to make your community a better place." The final asset is "Cultural Respect/Life" contains three items (response options $1=$ not at all like you; $2=$ a little like you; 3 = mostly like you; 4 = very much like you); a sample item is "You respect the beliefs of people even if they are of a different race." In this study, the Cronbach's alphas for the eight asset subscales are .76 (Family Communication), .80 (Peer Role Models), .55 (Future Aspirations), .71 (Responsible Choices), .74 (Non-Parental Role Models), .90 (Spirituality), .88 (Community Involvement), and .76 (Cultural Respect/Life).

\section{Brief Multidimensional Students' Life Satisfaction Scale (BMSLSS-C)}

The BMSLSS-C consists of one item for each of 7 life satisfaction domains (i.e., family, friends, school, self, 
living environment, romantic relationships, physical appearance) determined to be valid and reliable in college students [38]. The item assessing satisfaction in one's family life is "I would describe my satisfaction with my family life as," whereas "I would describe my satisfaction with my physical appearance as" assesses physical appearance satisfaction and so forth. Response options are from the widely used Delighted-Terrible Scale [39] and include $1=$ terrible, $2=$ unhappy, $3=$ mostly dissatisfied, $4=$ mixed (about equally satisfied and dissatisfied), $5=$ mostly satisfied, $6=$ pleased, and 7 $=$ delighted. Although a global life satisfaction item can also be used as a part of the BMSLSS-C, it was not included in the study due to redundancy. The Cronbach's alpha for BMSLSS-C in this study is .80 .

The Centers for Disease Control and Prevention's HRQOL-14 The HRQOL-14 is based on research with adults age 18 or older. The original survey consisted of four core questions on the Behavioral Risk Factor Surveillance System (BRFSS) [40,41]. Item 1 focuses on self-perceived health with response options of "excellent," "very good," "good," "fair," and "poor." Items 2 and 3 relate to recent physical and mental health symptoms and are considered mutually exclusive and were worded as such: "Now thinking about your physical (or mental) health, for how many days during the past 30 days was your physical (or mental) health not good?" Item 4 is conceptualized as a global measure of disability that explicitly incorporates both physical and mental health: "During the past 30 days, on how many days did poor physical or mental health keep you from doing your usual activities ...?" In 1995, an optional 10-item set of health perception and activity limitation items was added to the BRFSS. These items cover areas such as sleep, anxiousness/worrying, pain, and feeling full of energy (all during the past 30 days). All response options to the scale "days" items were identical and assessed the number of days that symptoms were experienced: 0 days, 1-2 days, 3 to 5 days, 6 to 9 days, 10 to 19 days, 20 to 29 days, and all 30 days.

Hennessey et al. [41] originally established the construct validity of the four core questions. Additional validation research has revealed that the HRQOL-14 demonstrated good construct, criterion, and knowngroups validity and that it could be considered for both surveillance and research applications when compared to the Rand Corporation's Short Form-36 (SF-36) [42]. The SF-36[43] is generally considered the "gold standard" for quality of life (QOL) research. Other validity research found the HRQOL-14 identified known or suspected population groups with unmet health-related needs, including those who reported chronic health conditions, disabilities, and low socioeconomic status (SES) [44-46]. The HRQOL scale also exhibits validity among college students [47]. Reliability studies reveal considerable test-retest reliability $[48,49]$.

\section{Data Analysis \\ Analysis Plan}

Multiple structural equation models (SEM) examined the proposed relationships among the developmental assets, life satisfaction, and HRQOL. The relationships between the constructs were assessed using Mplus version 4.21 [50] using maximum likelihood estimation. SEM procedures were selected for this investigation because they offer several advantages over traditional multivariate methods (e.g., ANOVA, MANOVA, etc.). First, because most outcomes (HRQOL and life satisfaction) have multiple predictors (developmental assets) that interact, SEM examines dependent and independent variables at once. Second, SEM procedures allow for the inspection of relationships among latent variables (underlying, but not directly measured) and multiple observed measures.

Models were proposed based upon theoretical predictions and examined using the following criteria: (1) theoretical salience, (2) global fit indices (chi-square goodness of fit, Comparative Fit Index: CFI \& TuckerLewis Index: TLI), (3) microfit indices (parameter estimates, Root Mean Squared Error of Approximation: RMSEA, and residuals), and (4) parsimony. Theoretical fit was examined with respect to documented theory and previous research. For the global fit indices, a nonsignificant chi-square indicates that the data does not significantly differ from the hypotheses represented by the model; for CFI and TLI, fit indices of above 0.90 (preferably above 0.95 ) are the criteria utilized to indicate a well-fitting model (CFI: [51]; TLI: [51]). For RMSEA, a fit of less than 0.05 indicates a well-fitting model [52]. Finally, requiring parsimony leads to the retention of a model with the fewest parameters that still meet the other criteria.

\section{Results \\ Descriptive Statistics HRQOL}

A majority of the participants reported "excellent" or "very good" self-rated health (70.28\%). Days in the past month where the participants' mental health was not good were: 0 days $-21.71 \%$; $1-2$ days $-32.03 \%$; $3-5$ days - $21.31 \%$; 6 + days $22.95 \%$. Days in the past month where the participants' physical health was not good were: 0 days - 24.21\%; $1-2$ days - $36.32 \%$; 3-5 days $22.46 \%$; $6+$ days $-17.02 \%$. Days in the past month where participants' mental and physical health was keeping them from their normal activities were: 0 days 47.07\%; $1-2$ days - $31.97 \%$; $3-5$ days - $12.43 \%$; $6+$ days $8.53 \%$. Days in the past month where the participants' 
felt worried, tense, or anxious were: 0 days $-8.02 \%$; $1-2$ days - 26.56\%; 3-5 days - 23.53\%; $6+$ days $-41.89 \%$. Days in the past month where the participants' did not get enough sleep were: 0 days $-2.85 \%$; 1 -2 days $10.52 \%$; $3-5$ days $-20.68 \%$; 6 + days $-65.95 \%$. Finally, days in the past month where the participants' felt very healthy and full of energy were: 0 days $-1.96 \% ; 1-2$ days - 7.86\%; $3-5$ days $-13.39 \%$; $6+$ days $-79.78 \%$.

\section{Life Satisfaction}

Means and standard deviations were calculated for the BMSLSS-C domains (Table 2). There was little variation among the mean scores for the Friendships, School, Self, Living Environment, and Physical Appearance domains with most falling within "mostly satisfied." The exception was the Family domain, which participants reported being "pleased." Some greater variation was also observed in the Romantic Relationships domain.

\section{Developmental Assets}

Similar to previous research [36,37], a cut-off system was derived to separate the students into those who had specific developmental assets and those who did not. For Family Communication, Peer Role Models, Future Aspirations, Responsible Choices, and Community Involvement, individuals with a score higher than 2 (thereby selecting 2: usually/very important/mostly like you or 3: almost always/extremely important/very much like you) were interpreted as having the asset. With respect to Non-parental Adult Role Models and Cultural Respect/Life, individuals with a score 1 or lower (indicating a selection of 0 : strongly agree or 1 : agree) would have the asset. In terms of Spirituality, a score of 2 or lower (2: agree and 1: strongly agree) would represent the presence of the asset. Table 3 presents the percent of students with each developmental asset. Over $7 \%$ of the students reported possessing none of the developmental assets while $3.9 \%$ reported possessing all eight assets.

\section{Structural Equation Models}

The final models resulting from the SEM procedures eliminated some items from the developmental asset measure and the HRQOL-14 due to model global fit indices, microfit indices, or parsimony. Items removed

Table 2 Mean BMSLSS-C scores

\begin{tabular}{lll}
\hline & M & SD \\
\hline Family & 6.08 & 1.04 \\
Friendships & 5.87 & 1.05 \\
School & 5.29 & 1.22 \\
Self & 5.49 & 1.19 \\
Environment & 5.23 & 1.32 \\
Romantic Relationships & 4.95 & 1.66 \\
Physical Appearance & 4.95 & 1.24 \\
\hline
\end{tabular}

Table 3 Distribution of Developmental Assets

\begin{tabular}{lccc}
\hline Asset & Mean & SD & \% with Asset \\
\hline 1. Family Communication & 2.20 & .71 & 73.7 \\
2. Peer Role Models & 2.38 & .54 & 86.1 \\
3. Future Aspirations & 2.39 & .61 & 84.3 \\
4. Responsible Choices & 2.59 & .41 & 95.5 \\
5. Non-parental Adult Role Models & 1.23 & .67 & 50.5 \\
6. Spirituality & 1.69 & 1.13 & 35.9 \\
7. Community Involvement & 1.46 & .79 & 30.7 \\
8. Cultural Respect/Life & 1.22 & .59 & 51.0 \\
\hline
\end{tabular}

from the developmental asset measure were from the constructs of Spirituality ("I am very spiritual" and "I am very religious") and Cultural Respect ("I respect the beliefs of people even if they are of a different race"). Items eliminated from the HRQOL-14 were questions about physical health status and included self-rated health, days of poor physical health, and days full of energy. No items from the BMSLSS-C were eliminated from the final models.

Variations of the final model as predicted by theory were examined (contact the primary author for a table of results of all models tested). The primary goal of the proposed models was to use the Developmental Assets to simultaneously predict HRQOL and Life Satisfaction. Figure 1 presents the final model and parameter estimates. The final model fit the data well, $\chi^{2}(n=581,515)=1252.23, \mathrm{CFI}=.94, \mathrm{TLI}=.93$, RMSEA $=.05$.

Three significant pathways are demonstrated in Figure 1. First, respondents who reported higher levels of Family Communication also reported higher life satisfaction. Second, individuals who reported higher levels of Future Aspirations also indicated poorer mental HRQOL days. Finally, the third significant pathway in the model suggests that in the sample, the developmental asset of Non-Parental Role Models is indirectly related to decreased life satisfaction and directly related to poor mental HRQOL days.

\section{Invariance Tests of the Model across Gender}

Initial tests examined the dependent variables across gender (see Figure 2). In Figure 2, estimates for males and females are provided for each variable, with female estimates in parentheses. Male participants were more likely to report zero poor mental health days than female participants, $\chi^{2}(n=562,6)=20.28$, $p=.002$. Men and women did not differ significantly on their health keeping them from their daily activities, $\chi^{2}(n=563,6)=11.86, p=.07$. Women reported more days that they felt tense or anxious in comparison to the men, $\chi^{2}(n=561,6)=38.07, p<.001$. There were no gender differences on the number of 


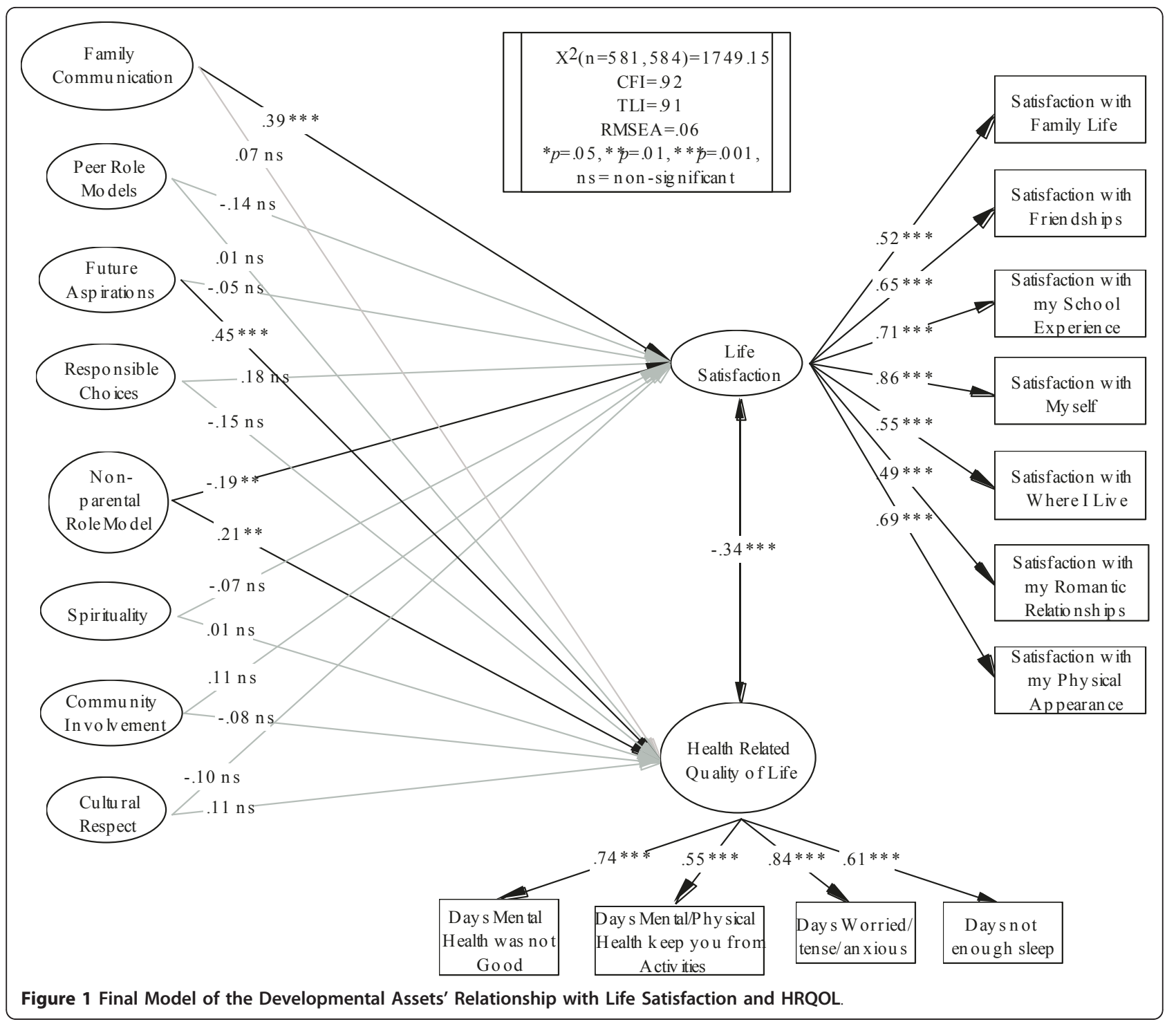

days not getting enough sleep, $\chi^{2}(n=561,6)=2.72, p$ $=.84$ or on any of the BMSLSS-C items, (Males: $n=$ 160, $M=38.39, S D=6.42$; Females: $n=400, M$ $=37.68, S D=5.67), t(558)=1.29, p=.20$, Cohen's $\mathrm{d}=.12$.

Tests of factorial invariance were performed on the final model, and the overall chi-square was significant, $\chi^{2}(1055)=2591.68, p<.001$, CFI $=.96$, TLI $=.95$, RMSEA $=.06$. For both models, the male and female participants' Family Communication predicted Life Satisfaction, and both Future Aspirations and Non-Parental Role Models predicted poor Mental HRQOL. In the male participant model only, Future Aspirations predicted Life Satisfaction. In the female participant model only, Responsible Choices predicted Life Satisfaction. The model examining invariance across male and female participants is presented in Figure 2.

\section{Discussion}

Previous research has explored the relationships between developmental assets and a variety of risk behaviors $[7,9-12,36,37,53,54]$. This body of research collectively suggests that the greater number of assets an adolescent possesses, the more they are protected against maladaptive behavior. Life satisfaction research [21-23,25,28] also suggests a similar relationship, which is why life satisfaction has been suggested to be an important health outcome [29]. HRQOL is an important protective health construct against behaviors such as unsafe alcohol use in college students [47]. However, no prior research has attempted to examine the concurrent relationships between developmental assets and both life satisfaction and HRQOL. Therefore, understanding how each of these important areas relates to one another has important implications for health promotion practice. 


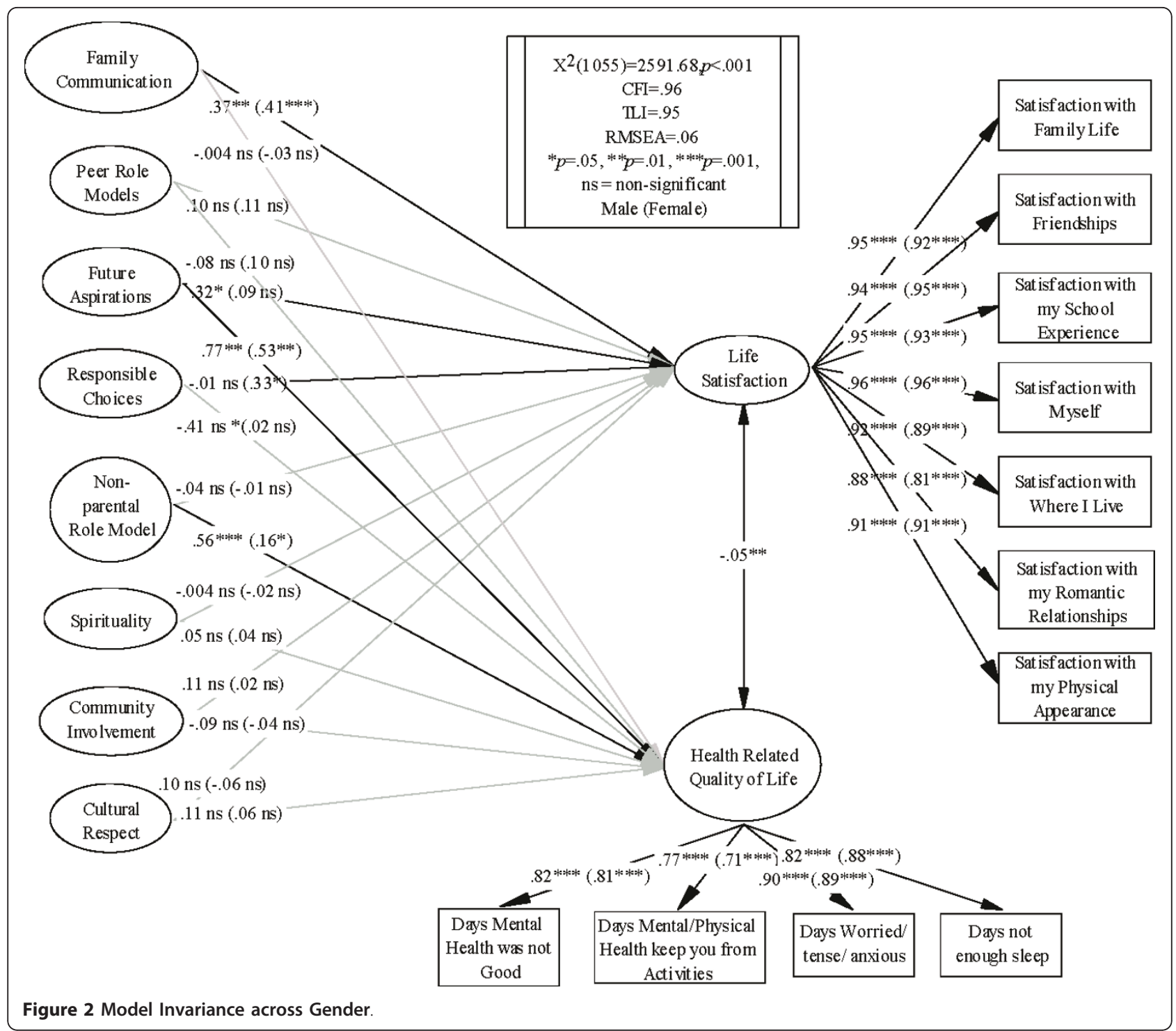

The present study extends the previous literature to college students and offers additional support for the connection between positive family communication and increased life satisfaction. Specifically, positive family support, parental acceptance, and communication are among the most influential factors determining life satisfaction among adolescents [55,56]. In addition, parental support and positive reinforcement help to smooth the transition into college and reduce student levels of loneliness, increase psychological adjustment, and increase academic achievement. Not surprisingly, there is also positive relationship between increased levels of life satisfaction and positive psychosocial functioning [55].

Conversely, the findings pertaining to Non-Parental Role Models and Future Aspirations were somewhat unexpected. The results from this investigation indicate that Non-Parental Role Models had a significant relationship with decreased life satisfaction, as well as a significant positive relationship with poor mental HRQOL days (e.g., days worried or tense). Prior research has indicated that the presence of developmental assets such as Non-Parental Role Models and adult support play an important role in overall adolescent development [57]. Constructive-natured relationships with adults have also been related to positive outcomes in younger samples of adolescents $[58,59]$ and positive outcomes in teenagers.

However, Beam et al. [58] found that high school students who utilized non-parental role models (or "very important people") did not seek these relationships as a means to deal with personal challenges (such as poor mental HRQOL). Rather, it was determined that students formed the associations out of normal daily circumstances. In other words, Beam et al. [58] found that 
utilization of non-parental adult relationships had very little to do with the student's own personal problems. Although somewhat speculative, the high school environment, where students find themselves in the presence of non-parental adults for the majority of the day, may be different from the college environment where students lead more independent schedules and are older in age. Thus, it is not surprising that school climate research has identified student-adult relationships as one of the most important domains for high school and middle school students $[60,61]$ because students have interactions with non-parental adults as an intrinsic characteristic of their surroundings.

In contrast, students in college settings without specialized arrangements such as faculty-in-residence programs [62] may not have the opportunity to take advantage of such relationships with potential non-parental role models. Programs such as faculty-in-residence programs may offer students a mode of existence that is reminiscent of the naturally occurring environment within high schools. A supplementary point of interest lies in the limitations of student benefits for those relying solely on a formal classroom setting as a medium for interactions. For example, the degree of formality in a collegiate classroom has shown to be less effective [in regards to student outcomes] in comparison to informal interplay between professors and students [63]. However, even with the benefits of casual professor-student relationships documented, methods for novel ways to efficiently encourage these interactions remain a challenge [62]. In sum, interactions with potential non-parental role models in college settings may be naturally less supportive, which may increase poor mental HRQOL days as a result.

The finding in relation to Future Aspirations predicting poor mental HRQOL was also unexpected. Previous research indicates that the development of future aspirations within an individual is correlated with a healthier level of development and lower likelihood of engaging in risk-taking behavior in high school students $[10,11]$. Quaglia and Cobb [64] define future aspirations as "a student's ability to identify and set goals for the future, while being inspired in the present to work toward those goals." During an adolescent's high school years, serious consideration in regards to future education and occupation often commences [65]. Numerous factors such as media influence (i.e. implied career prestige), family attitudes, academic engagement and achievement, and peer-related gender stereotypes (such as the schema that women become nurses and men become physicians) play a role in the formation of occupational future aspirations $[65,66]$. Although tentative, college students may harbor a greater temporal urgency for the rigors of the work world and may be more cognizant of the barriers of entry into an increasingly competitive workforce. The educational mission of college may further intensify these concerns in relation to those of high school, which may in turn cause greater worry, anxiety, and loss of sleep, which then reduces mental HRQOL.

\section{Study Limitations}

Limitations to the present study include a Caucasian sample of university students representing one Midwestern university. Additional investigations should be conducted in more diverse university populations in different geographic regions in both urban and rural settings, as findings reported here may yield different results in different populations of university students. In addition, several developmental asset measures contained only two items either to begin with (e.g., Future Aspirations) or because of our model parameters led to item exclusion within a construct (e.g., Cultural Respect/Life). Considering that one of the significant pathways in the final model was Future Aspirations, results here should be interpreted cautiously. Finally, a $56 \%$ response rate was achieved in this study, which may limit the generalizability of the findings.

\section{Conclusions}

Guthman et al. [67] found during a 12-year comparative study that college students are experiencing higher levels of mental distress than what was witnessed a decade ago. However, the determination of exactly what catalyzed the increase in rates of severe depression, anxiety and emotional turmoil in college students requires further investigation. The analysis of these findings by colleges and universities may prove useful for the amelioration of current standards which may have encouraged deficiencies in these important facets wellbeing (e. g., school programs which indirectly lead to limited family communication). In addition, developing a deeper understanding of the source of the aforementioned findings is useful in assisting universities with the aim of lowering attrition rates. Decreasing attrition among the student body is a commonly found when student concerns bear a direct influence on the adaptation of campus policies - such as determining standards regarding the quality of dormitory living facilities [68]. It should also be noted here that life satisfaction levels among college students were able to significantly predict academic retention by themselves, but also in combination with overall grade point averages (GPA) 1-3 years in advance [69]. Hence, future studies might seek to extend the models in this study by including longitudinal constructs and retention rates.

Likewise, the results of this study may be utilized for examining the type of support non-parental role models are providing students in colleges. While students may 
have frequent contact with academic advisors and instructional faculty who provide them informational support, students may also need other forms of social support such as emotional (e.g., trust, caring, etc.), instrumental support (aid that directly assists a person in need), and appraisal support (constructive feedback, affirmation, etc.) that have been shown to improve health outcomes [70,71]. Establishing a framework for meetings where multiple forms of support are displayed by non-parental role models at set intervals may not only reestablish the nature of the relationships of those observed in high school students (e.g., [58]), but also may prove useful over potentially waiting for personal problems to develop. Furthermore, the results of this research may help guide effective additional activities, such as community and family support programs [72] which have been established as a fruitful endeavor towards the main goal of improving the overall QOL of the campus student body [73].

\section{Abbreviations}

BMSLSS-C: Brief Multidimensional Students' Life Satisfaction Scale; BRFSS: Behavioral Risk Factor Surveillance System; HRQOL: health-related quality of life; PYD: Positive youth development; QOL: quality of life; SEM: structural equation models; SF-36: Rand Corporation's Short Form-36; US CDC: United States Centers for Disease Control and Prevention

\section{Author details}

'Department of Community Medicine, West Virginia University, Morgantown, W, USA. ${ }^{2}$ Department of Kinesiology and Health, Miami University of Ohio, Oxford, $\mathrm{OH}$, USA.

\section{Authors' contributions}

KJZ conceived and designed the study, collected the data, participated in the analysis and interpretation of the data, and coordinated all aspects of the manuscript. DAT participated in drafting the manuscript. RMW participated in the analysis and interpretation of the data and in drafting the manuscript. All parties have received the manuscript and have reviewed it.

\section{Competing interests}

The authors declare that they have no competing interests.

Received: 11 April 2011 Accepted: 13 July 2011 Published: 13 July 2011

\section{References}

1. Roth J, Brooks-Gunn J, Murray L, Foster W: Promoting health adolescents: Synthesis of youth development program evaluation. J Adolesc Res 1998, 8:423-459.

2. Benson PL, Scales PC, Hamilton SF, Sesma A Jr, Hong KL, Roehlkepartain EC Positive youth development so far: Core hypotheses and their implications for policy and practice. Search Institute Insights \& Evidence 2006, 3(1):1-13.

3. Roehlkepartain EC, Hong KL, Scales PC: Boosting student achievement by building developmental assets: new research strengthens the case. Minnesota School Boards Association Journal 2005, 58:16-18.

4. Scales PC, Leffert N: Developmental assets: A synthesis of the scientific research on adolescent development. Minneapolis, MN: Search Institute; 1999.

5. Sesma A Jr, Roehlkepartain EC: Unique strengths, shared strengths: Developmental assets among youth of color. Search Institute Insights \& Evidence 2003, 1(2):1-13.

6. Lerner RM: Theories of human development: Contemporary perspectives. In Handbook of child psychology: Theoretical models of human development.
Volume 2.. 5 edition. Edited by: Damon W, Lerner RM. New York: Wiley; 1998:1-24.

7. Benson PL, Scales PC, Hawkins JD, Oesterle S, Hill KG: Executive Summary: Successful Young Adult Development. 2004, 1-23.

8. Aspy CB, Oman RF, Vesley SK, McLeroy K, Rodine S, Marshall L: Adolescent violence: The protective effects of youth assets. J Couns Dev 2004, 82:269-277.

9. Atkins L, Oman RF, Vesley S, Aspy CB, McLeroy K: Adolescent tobacco use: The protective effects of developmental assets. Am J Health Promot 2002, 16:198-205.

10. Oman RF, Vesley SK, Aspy CB, McLeroy K, Luby C: The association between multiple youth assets and sexual behavior. Am J Health Promot 2004, 19(1):12-18.

11. Vesly SK, Wyatt VH, Oman RF, Aspy CB, Kegler MC, Rodine S, Marshall L, McLeroy KR: The potential protective effects of youth assets from adolescent sexual risk behaviors. J Adolesc Health 2004, 34:356-365.

12. Oman RF, Vesely S, Aspy CB, McLeroy KR, Rodine S, Marhsall L: The protective effect of youth assets on adolescent alcohol and drug use. Am J Public Health 2004, 94:1425-1430.

13. Pancer SM, Hunsberger B, Pratt MW, Alistat S: Cognitive complexity of expectations and adjustment to university in the first year. $J$ Adolesc Res 2000, 15:38-57.

14. Wintre MG, Yaffe Y: First-year students' adjustment to university life as a function of relationships with parents. J Adolesc Res 2000, 15:9-37.

15. Roehlkepartain EC, Benson PL, Sesma A: Signs of Progress in Putting Children First: Developmental Assets among Youth in St. Louis Park, 1997-2001. 2003, 1-61.

16. Diener E: Subjective well-being: The science of happiness and a proposal for a national index. Am Psychol 2000, 55:34-43.

17. Zullig KJ, Valois RF, Huebner ES, Drane JW: Associations among family structure, demographics and adolescent perceived life satisfaction. $J$ Child Fam Stud 2005, 14:195-206.

18. Diener E, Suh E, Oishi S, Lucas R, Smith HL: Subjective well-being: Three decades of progress. Psychol Bull 1999, 125:276-302.

19. Pavot W, Diener E: Review of the satisfaction with life scale. Psychol Assessment 1993, 5(2):164-172.

20. Centers for Disease Control and Prevention: Measuring Healthy Days. Atlanta; 2000, 8.

21. Valois RF, Zullig KJ, Huebner ES, Drane JW: Relationship between life satisfaction and violent behaviors among adolescents. Am J Health Behav 2001, 25(4):353-366

22. Zullig KJ, Valois RF, Huebner ES, et al: Relationship between perceived life satisfaction and adolescents' substance abuse. J Adolesc Health 2001, 29:279-288.

23. Valois RF, Zullig KJ, Huebner ES, Kammermann SK, Drane JW: Relationship between of life satisfaction and sexual risk-taking behaviors among public high school adolescents. J Child Fam Stud 2002, 11(4):427-440.

24. Esch LM, Zullig KJ: Middle school students' weight perceptions, dieting behaviors, and life satisfaction. American Journal of Health Education 2008, 39:345-352.

25. Valois RF, Zullig KJ, Huebner ES, Drane JW: Relationship between perceived life satisfaction and dieting behavior among public high school adolescents. Eating Disorders: The Journal of Treatment and Prevention 2003, 11:271-288.

26. Zullig KJ, Pun SM, Huebner ES: Life satisfaction, dieting behavior, and weight perceptions among college students. Applied Research in Quality of Life 2007, 2:17-31.

27. Valois RF, Zullig KJ, Huebner ES, Drane JW: Life satisfaction and suicide among high school adolescents. Soc Indic Res 2002, 64(3):1-25.

28. Valois RF, Zullig KJ, Huebner ES, Drane JW: Physical activity behaviors and perceived life satisfaction among public high school adolescents. J Sch Health 2004, 74(2):59-65.

29. Huebner ES, Valois RF, Suldo SM, Smith LC, McKnight CG, Seligson JJ, et al: Perceived quality of life: a neglected component of adolescent health assessment and intervention. J Adolesc Health 2004, 34(1):1-9.

30. Valois RF, Zullig KJ, Huebner ES, Drane JW: Youth developmental assets and perceived life satisfaction: Is there a relationship? Applied Research Quality Life 2009, 4:315-331.

31. Centers for Disease Control and Prevention: Behavioral Risk Factor Surveillance System (BRFSS).[http://www.cdc.gov/hrqol/]. 
32. Collishaw S, Maughan B, Goodman R, Pickles A: Time trends in adolescent mental health. J Child Psychol Psychiatry 2004, 45(8):1350-1362.

33. Twenge JM: Generation Me: Why Today's Young Americans Are More Confident, Assertive, Entitled - and More Miserable than Ever Before. New York: Free Press; First 2007.

34. SAS Institute Inc: SAS ${ }^{\oplus}$ 9.1.3 User's Guide. Cary, NC: SAS Institute Inc; 2006.

35. Pealer LN, Weiler RM, Pigg RM, Dorman S: The feasibility of a web-based surveillance system to collect risk behavior data from college students. Health Educ Behav 2001, 28(5):547-559.

36. Oman RF, Vesley SK, McLeroy KR, Harris-Wyatt V, Aspy CB, Rodine S, Marshall L: Reliability and validity of the youth asset survey (YAS). $J$ Adolesc Health 2002, 3(1):247-255

37. Zullig KJ, Ward RM, King KA, Patton JM, Murray KM: Testing the Feasibility of Developmental Asset Measures on College Students to Guide Health Promotion Efforts. Assessment 2009, 16(1):31-41.

38. Zullig KJ, Huebner ES, Patton JM, Murray KA: The Brief Multidimensional Student's Life Satisfaction Scale-College version. Am J Health Behav 2009, 33(5):483-493.

39. Andrews FM, Withey SB: Social Indicators of Well-Being: Americans' Perceptions of Life Quality. New York: Plenum; 1976.

40. Centers for Disease Control and Prevention: Quality of Life as a New Public Health Measure-Behavior Risk Factor Surveillance System. MMWR Morb Mortal Wkly Rep 1994, 43(20):375-380.

41. Hennessy CA, Moriarty DG, Zack MM, et al: Measuring health-related quality of life for public health surveillance. Pub Health Rep 1994, 109(5):665-672.

42. Issued by Centers for Disease Control and Prevention (US), Newschaffer CJ: Validation of the BRFSS HRQOL measures in a statewide sample. Final Report. Atlanta (GA): Department of Health and Human Services (US), Office of Disease Prevention and Health Promotion; Prevention Centers Grant No. U48/CCU710806-01; 1998.

43. Ware JE, Sherbourne DC: The MOS 36-item Short Form Health Survey (SF36): Conceptual framework and item selection. Med Care 1992, 30(6):473-483.

44. Andresen EM, Fouts BS, Romeis JC, et al: Performance of health-related quality-of-life instruments in a spinal cord injury population. Arch Phys Med Rehabil 1999, 80:877-884.

45. Diwan S, Moriarty D: A conceptual framework for identifying unmet health care needs of community dwelling elderly. J App/ Gerontol 1995, 14(1):47-63.

46. Nanda U, Andresen EM: Performance measures of health-related quality of life and function among disabled adults [abstract]. Qual Life Res 1998 7:644

47. Zullig KJ: Using the centers for disease control and prevention's core health-related quality of life scale on a college campus. Am J Health Behav 2005, 29(6):569-578.

48. Andresen EM, Catlin TK, Wyrich KW, et al: Retest reliability of surveillance questions on health related quality of life. J Epidemiol Community Health 2003, 57:339-343.

49. Kapp J, Jackson-Thompson J, Petroski G, et al: Reliability of health-related quality-of-life indicators in cancer survivors from a population-based sample, 2005, BRFSS. Public Health 2009, 123(4):321-325.

50. Muthén LK, Muthén BO: MPlus User's Guide. Los Angeles, CA: Muthén \& Muthén; 2007

51. Hu LT, Bentler PM: Cutoff criteria for fit indices in covariance structure analyses: Conventional criteria versus new alternatives. Structural Equation Modeling 1999, 6:1-55

52. Browne MW, Cudeck R: Alternative ways of assessing model fit. In Testing structural equation models. Edited by: Bollen KA, Long JS. Newbury Park, CA: Sage; 1993:136-162.

53. Edwards O, Mumford V, Shillingford M, Serra-Roldan R: Developmental Assets: A Prevention Framework for Students Considered at Risk. Children \& Schools 2007, 29(3):145-153

54. Leffert N, Benson P, Scales P, Sharma A, Drake D, Blyth D: Developmental Assets: Measurement and Prediction of Risk Behaviors Among Adolescents. Applied Developmental Science 1998, 2(4):209.

55. Suldo SM, Huebner S: The role of life satisfaction in the relationship between authoritative parenting dimensions and adolescent problem behavior. Soc Indic Res 2004, 66(1-2):165-195.

56. Seibel FL, Johnson WB: Parental control trait anxiety and satisfaction with life in college students. Psychol Rep 2001, 88:473-480.
57. Greenberger $E$, Chen $C$, Beam MR: The role of very important nonparental adults in adolescent development. J Youth Adolesc 1997, 27(3):321-343.

58. Beam M, Chuansheng C, Greenberger E: The Nature of Adolescents' Relationships With Their 'Very Important' Nonparental Adults. Am J Community Psychol 2002, 30(2):305.

59. Chew W, Osseck J, Raygor D, Eldridge-Houser J, Cox C: Developmental Assets: Profile of Youth in a Juvenile Justice Facility. J Sch Health 2010, 80(2):66-72.

60. Ito A, Smith DC: Predictors of school satisfaction among Japanese and US youth. The Community Psychologist 2006, 38:19-21.

61. Zullig K, Koopman TM, Patton JM, Ubbes VA: School climate: historical review instrument development \& school assessment. J Psychoeduc Assess 2010, 28(2):139-152.

62. Bradley EC, Elizabeth O: Faculty-Student Interaction Outside the Classroom: A Typology from a Residential College. Review of Higher Education 2007, 30(4):343-362.

63. Cotton SR, Wilson B: Student-faculty interactions: Dynamics and determinants. Higher Education 2006, 51:487-519.

64. Quaglia RJ, Cobb CD: Toward a theory of student aspirations. Journal of Research in Rural Education 1996, 12(3):127-132.

65. Mei T, Wei P, Newmeyer MD: Factors Influencing High School Students' Career Aspirations. Professional School Counseling 2008, 11(5):285-295.

66. Creed PA, Conlon EG, Zimmer-Gembeck MJ: Career barriers and reading ability as correlates of career aspirations and expectations of parents and their children. Journal of Vocational Behavior 2007, 70:242-258.

67. Guthman JC, locin L, Konstas D: Proceedings of Increase in Severity of Mental Illness Among Clinical College Students: A 12-Year Comparison San Diego; 2010.

68. Davidson WB, Beck HP, Milligan M: The College Persistence Questionnaire: Development and Validation of an Instrument That Predicts Student Attrition. J Coll Stud Dev 2009, 50(4):373-390.

69. Frisch MB, Clark MP, Rouse SV, Rudd MD, Paweleck JK, Greenston A Kopplin DA: Predictive and treatment validity of life satisfaction and the quality of life inventory. Assessment 2005, 12:66-78.

70. Berkman LF, Glass T: Social Integration Social Networks Social Support and Health. In Social Epidemiology. Edited by: Berkman LF, Kawachi I. New York: Oxford University Press; 2000:

71. Uchino B: Social support and health: A review of the physiological processes potentially underlying links to disease outcomes. J Behav Med 2006, 29:377-387.

72. Scales PC: The Role of family support programs in building developmental assets among young adolescents: a national survey of services and staff training needs. Child Welfare 1997, 76(5):611-635.

73. Scales PC, Roehlkepartain EC: Boosting student achievement: New research on the power of developmental assets. Search Institute Insights \& Evidence 2003, 1(1):1-10.

doi:10.1186/1477-7525-9-52

Cite this article as: Zullig et al:: Not all developmental assets are related to positive health outcomes in college students. Health and Quality of Life Outcomes 2011 9:52.

\section{Submit your next manuscript to BioMed Central and take full advantage of:}

- Convenient online submission

- Thorough peer review

- No space constraints or color figure charges

- Immediate publication on acceptance

- Inclusion in PubMed, CAS, Scopus and Google Scholar

- Research which is freely available for redistribution

Submit your manuscript at www.biomedcentral.com/submit
C Biomed Central 